\title{
Ammonium Secretion During Colletotrichum coccodes Infection Modulates Salicylic and Jasmonic Acid Pathways of Ripe and Unripe Tomato Fruit
}

\author{
Noam Alkan, ${ }^{1,2}$ Robert Fluhr, ${ }^{2}$ and Dov Prusky ${ }^{1}$ \\ ${ }^{1}$ Department of Postharvest Science of Fresh Produce, Agricultural Research Organization, the Volcani Center, Bet Dagan \\ 50250, Israel; ${ }^{2}$ Department of Plant Sciences, Weizmann Institute of Science, Rehovot, Israel
}

Submitted 6 February 2011. Accepted 8 September 2011.

The postharvest pathogens Colletotrichum coccodes remains quiescent after infection of unripe fruit. However, during fruit ripening, the pathogen assumes a necrotrophic life style, rapidly colonizing the tissue. $C$. coccodes secretes ammonium during germination and colonization of host tissue that induces host programmed cell death. We further examined the role of ammonia in the infection process by analyzing transcriptome expression from infected and ammonia-treated fruit tissue compared with healthy tissue. The analysis revealed 82 and 237 common upregulated and downregulated genes, respectively. Quantitative reverse-transcriptase polymerase chain reaction analysis of select transcripts in normal and transgenic NADPH oxidase antisense plants revealed that their expression was NADPH oxidase dependent. Common-upregulated genes showed overrepresentation of salicylic acid (SA)-dependent genes as well as genes related to biotic stress. The downregulated genes showed overrepresentation of jasmonic acid (JA)-dependent genes. Indeed, direct application of SA to the fruit enhanced $C$. coccodes necrotrophic colonization, whereas the application of JA delayed colonization. Importantly, green fruit and red fruit displayed similar gene expression patterns although only red fruit is susceptible to colonization. Thus, it is likely that the resistance of green fruit to $C$. coccodes colonization is due to additional factors.

Postharvest fungal pathogens exploit different routes to enter host tissue, including wounded surfaces, natural openings, and direct penetration. In ripe fruit, a pathogen can start its colonization process immediately after spores adhere to wounded tissue. In contrast, the same pathogen, after penetrating unripe fruit, can remain inactive for months until the fruit ripens. The period from host infection to the activation of fungal growth and symptom development is designated the quiescent phase (Prusky 1996; Prusky et al. 2009). During fruit storage and ripening, significant natural physiological changes occur that the pathogen can sense and respond to. These modifications include changes in tissue extracellular $\mathrm{pH}$ (e.g., in tomato from 6.7 to 4.4) (Almeida and Huber 1999), alterations in nutrient composition, and reduction in antifungal compounds.

Corresponding author: D. Prusky; Telephone: +972-3-9693610; Fax: +9723-9683622; E-mail: dovprusk@agri.gov.il

* The $\boldsymbol{e}$-Xtra logo stands for "electronic extra" and indicates that six supplementary figures and nine supplementary tables are published online.
Postharvest pathogens alter the $\mathrm{pH}$ of their environments, thus enhancing their ability to grow and cause disease. Each pathogen has an optimal $\mathrm{pH}$ for growth and pathogenicity (Prusky and Lichter 2007; Steven and Denison 2000). Penicillium, Sclerotinia, and Botrytis spp. and other fungi secrete organic acids that cause acidification (Hadas et al. 2007; Maxwell and Lumsden 1970: Rollins and Dickman 2001; Verhoeff et al. 1988) while Colletotrichum and Alternaria spp. and other fungi secrete ammonium that cause alkalinization of the environment (Eshel et al. 2002; Prusky et al. 2001). In tomato fruit, Colletotrichum coccodes infection increases the pH from 4.2 to 7.9 (Alkan et al. 2008). Ammonia is secreted by Colletotrichum spp. during all stages of their development (i.e., germination, appressoria formation, and necrotrophic growth) (Alkan et al. 2008; Miyara et al. 2010; Prusky and Yakoby 2003; Prusky et al. 2001). The source of ammonia is from deamination of amino acids (Alkan et al. 2008; Prusky and Yakoby 2003; Prusky et al. 2001). Secretion of ammonia is stimulated by $\mathrm{pH}$ of 4.0 (Alkan et al. 2008); however, lower $\mathrm{pH}$ inhibited fungal growth. In addition, ammonium enhances Colletotrichum spp. pathogenicity by transcriptional activation of fungal pathogenicity factors such as pectate lyase (Drori et al. 2003; Kramer-Haimovich et al. 2006).

Plants respond to the lifestyle of the pathogen, where salicylic acid (SA)- and jasmonic acid (JA)-dependent pathways play important signaling roles. One salient feature of defense against biotrophs is programmed cell death (PCD) and accumulation of SA (Glazebrook 2005; Spoel et al. 2007). In contrast, necrotrophic pathogens benefit from host cell death, and their growth is contained by a different set of defense responses activated by JA and ethylene signaling pathways (Glazebrook 2005; Spoel et al. 2007).

Necrotrophic fungal pathogens can induce PCD by secreting toxins (Colmenares et al. 2002; De-León et al. 2007; Keller et al. 1996; MacKinnon et al. 1999; Otani et al. 1998; Stone et al. 2000), elicitors (El-Maarouf et al. 2001), or cell wall products (Cabrera et al. 2006; Matsumura et al. 2003). Agents that modulate the $\mathrm{pH}$ of the infection court, such as oxalic acid secreted by Sclerotinia sclerotiorum (Kim et al. 2008) and ammonium secreted by $C$. coccodes (Alkan et al. 2009), have also been implicated in PCD. In this case, they can serve as enhancers of host reactive oxygen species (ROS) accumulation, promoting cell death and fungal virulence. A key element responsible for controlled ROS production in innate immune processes is the evolutionarily highly conserved NADPH oxidases, called respiratory burst oxidase homologs $(\mathrm{RBOH})$ in plants. Reduction in the expression of the tomato SIRBOH was shown to reduce wound response in systemic leaves (Sagi et al. 
2004). In addition, ammonia was shown to activate the plant membrane SIRBOH and rat NADPH oxidase (Alkan et al. 2009; Reinehr et al. 2007). Activation of SIRBOH by ammonia led to PCD and enhanced necrotrophic fungal colonization (Alkan et al. 2009). However, the exact mechanism involved needs to be elucidated. Ammonia secreted by $C$. coccodes can have additional effects on the host. Previous work has shown that ammonium indirectly activates transport of various host solutes, modulates concentrations of host cytosolic protons (Mathieu et al. 1994), and changes membrane flux processes (Britto and Kronzucker 2002).

The present work further describes the effects of ammonium secreted by $C$. coccodes on the tomato fruit response. Our findings indicate that fungal ammonification of the infection court activates host SA-sensitive genes and, at the same time, suppresses JA-sensitive genes in a SIRBOH-dependent manner. These processes occur both in green fruit that is resistant to pathogen colonization and in red fruit that is susceptible to infection. The results suggest that additional factors are important for dictating fungal transition from the quiescence stage to the necrotrophic stage.

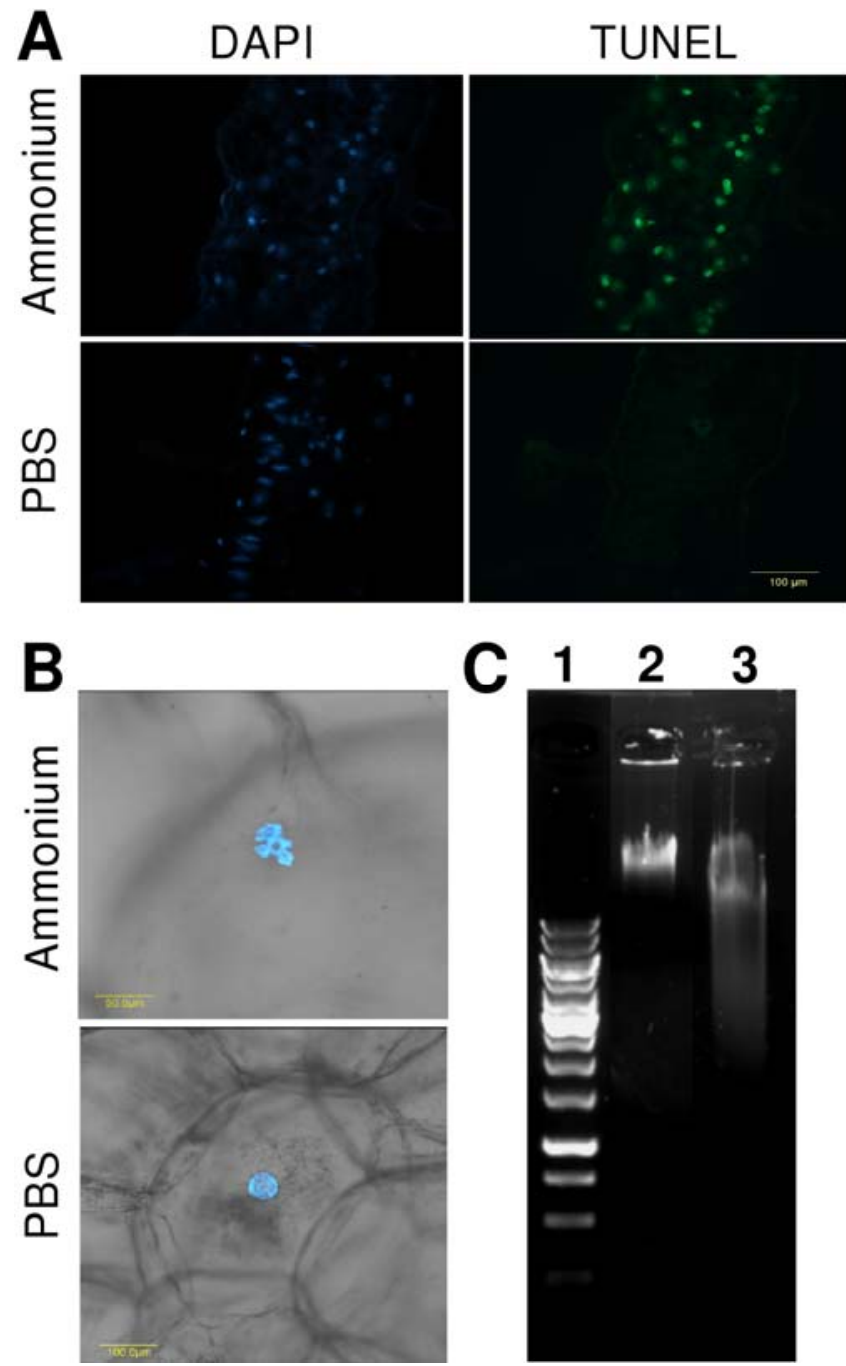

Fig. 1. Transferase-mediated dUTP nick end labeling (TUNEL), 4',6-diamidino-2-phenylindole (DAPI) staining, and DNA degradation of tomato tissues treated with ammonium or phosphate-buffered saline (PBS). A, Tissue was stained with DAPI or with TUNEL after ammonium (upper pictures) or PBS treatment (lower pictures). B, DAPI staining of fruit parenchyma nucleus treated with ammonium (upper picture) or PBS (lower picture). C, Fractionation of total DNA extracted from tomato fruit parenchyma: lane 1, 1-kb ladder; lane 2, PBS treatment; lane 3, ammonium treatment.

\section{RESULTS}

Transcriptome analysis of tomato fruit reacting to ammonia accumulation.

We have previously shown that application of ammonia or infection by $C$. coccodes initiated SIRBOH-dependent cell death (Alkan et al. 2009). We were interested in further elucidating the molecular events involved in this process. Tomato fruit parenchyma cells were infiltrated with $20 \mathrm{mM}$ ammonium chloride, a concentration that emulates in situ accumulation during infection, (Miyara et al. 2010). Transferase-mediated dUTP nick end labeling (TUNEL) staining was employed to monitor apoptotic-like cell death process. Inspection of the treated site $24 \mathrm{~h}$ later revealed extensive staining in treated leaves compared with control tissue (Fig. 1A). In addition, as determined by 4',6-diamidino-2-phenylindole (DAPI) staining, nuclear morphology irregularities were found in both ammonia treatments and $C$. coccodes infection (Fig. 1B; Supplementary Fig. S1). Prognostic degradation of nuclear DNA indicative of PCD was observed as well (Fig. 1C). Such partial and diffuse DNA degradation rather than a clear laddering pattern noted in mammalian PCD is common in plant PCD (Duan et al. 2010; Ge et al. 2005; Gunawardena et al. 2004; Lee and Chen 2002; Lombardi et al. 2007; Yen and Yang 1998). The results (Fig. 1) suggest an induction of a PCD-like process by the application of ammonium.

To further analyze commonalties between infection and ammonia application, we undertook transcriptome analysis of treated and control tomato fruit at the breaker stage (discussed below). The application of ammonia $(5 \mathrm{mM})$ did not affect the $\mathrm{pH}$ of the tomato fruit tissue compared with the phosphatebuffered saline (PBS) control. Because ammonia concentration declined slightly $(30 \%)$ within $3 \mathrm{~h}$, it was reapplied every $5 \mathrm{~h}$. The global analysis of our transcriptome data showed the highest Pearson's correlation between sample repeats and control repeats of wound and PBS treatment, respectively. In contrast, the greatest difference in correlation was between infection and wound control followed by ammonium and PBS control (Supplementary Fig. S2). A threshold for transcript induction range was set at $>1.5$-fold change and was then corrected for false discovery rate (FDR; $P$ value $<0.05$ ) (discussed below). In $C$. coccodes infection, 912 upregulated and 1,258 downregulated genes were detected in infected fruit compared with uninfected wounded control (Fig. 2). Of those genes, 636 upregulated and 731 downregulated genes were annotated according to the gene ontology (GO) terms of Arabidopsis (listed in Supplementary Tables 1 and 2). Tomato fruit treated by ammonium showed 237 upregulated and 367 downregulated genes compared with the PBS control (Fig. 2); of those, 165 upregulated and 226 downregulated genes were annotated (Supplementary Tables 3 and 4). Significantly, the overlapping gene set between the infection and ammonium experiments revealed 82 and 237 common upregulated and downregulated genes, respectively (Fig. 2). The possibility that these overlaps are the result of random events is $P$ value $<2.6 \times 10^{-28}$ and $3.1 \times$ $10^{-127}$, respectively, as tested by hypergeometric probability (discussed below). Of those common genes, 64 upregulated and 146 downregulated genes were annotated (Supplementary Tables 5 and 6).

The annotated genes in the overlapping groups were classified by "GO annotation" and by inspection of the literature. A subset $(45 \%)$ was classified as stress genes and its 4.6-fold overrepresentation was significant, with a $P$ value $<4.3 \times 10^{-15}$ $\left(\chi^{2}\right.$ test). Of those stress genes, $69 \%$ correlated with SA-type induced biotic stress (e.g., pathogen-related [PR]-induced genes and systemic acquired resistance [SAR]). They represent 22.7-fold overrepresentation that is significant with a $P$ value $<$ 
$2.4 \times 10^{-58}$ (Fig. 2). In contrast, the subset of overlapping downregulated genes showed that $34 \%$ of them were stress response genes (Fig. 2). Of those, 38\% were JA-responsive genes belonging to "wound response". This represents a 2.6 overrepresentation that is significant with a $P$ value $<5 \times 10^{-3}$. In summary, both ammonium treatment and infection of common upregulated genes exhibited overrepresentation of defense response genes (e.g., PR genes and SA-induced genes) while the common downregulated genes exhibited overrepresentation of JA-induced and wound response genes.

Inoculation of fruit with $C$. coccodes mutant strains and resultant gene expression patterns.

We wished to examine the quantitative effect on gene induction of various $C$. coccodes mutants. The mutants nit $t^{-}$and are $A^{-}$were shown to be defective in their ammonia production and were less virulent, while ammonia application to the infection site of those mutants restored their virulence (Alkan et al. 2008). To this end, representative up- or downregulated genes based on microarray data were chosen for examination by quantitative reverse-transcriptase polymerase chain reaction (qRT-PCR). The genes in the upregulated set were chosen because all were shown to be SA-dependent genes and included PR1 (AW218809) (Gu et al. 2002; Peng et al. 2004; Wildermuth et al. 2001), PR2 (BG631079) (glucan endo- $\beta$-glucosidase) (Gu et al. 2002; Li et al. 2005), hexokinase (AJ401153.1) (Kim et al. 2006; Sarowar et al. 2008), sucrose synthase (Su et al. 2009), chitinase II (Davis et al. 2002), and UDP-glucose glucosyltransferase (Enyedi and Raskin 1993). In a similar manner, a set of known downregulated genes that were shown to be correlated with JA accumulation was chosen and included lipoxygenase (U09026.1) (Heitz et al. 1997; Turner et al. 2002),
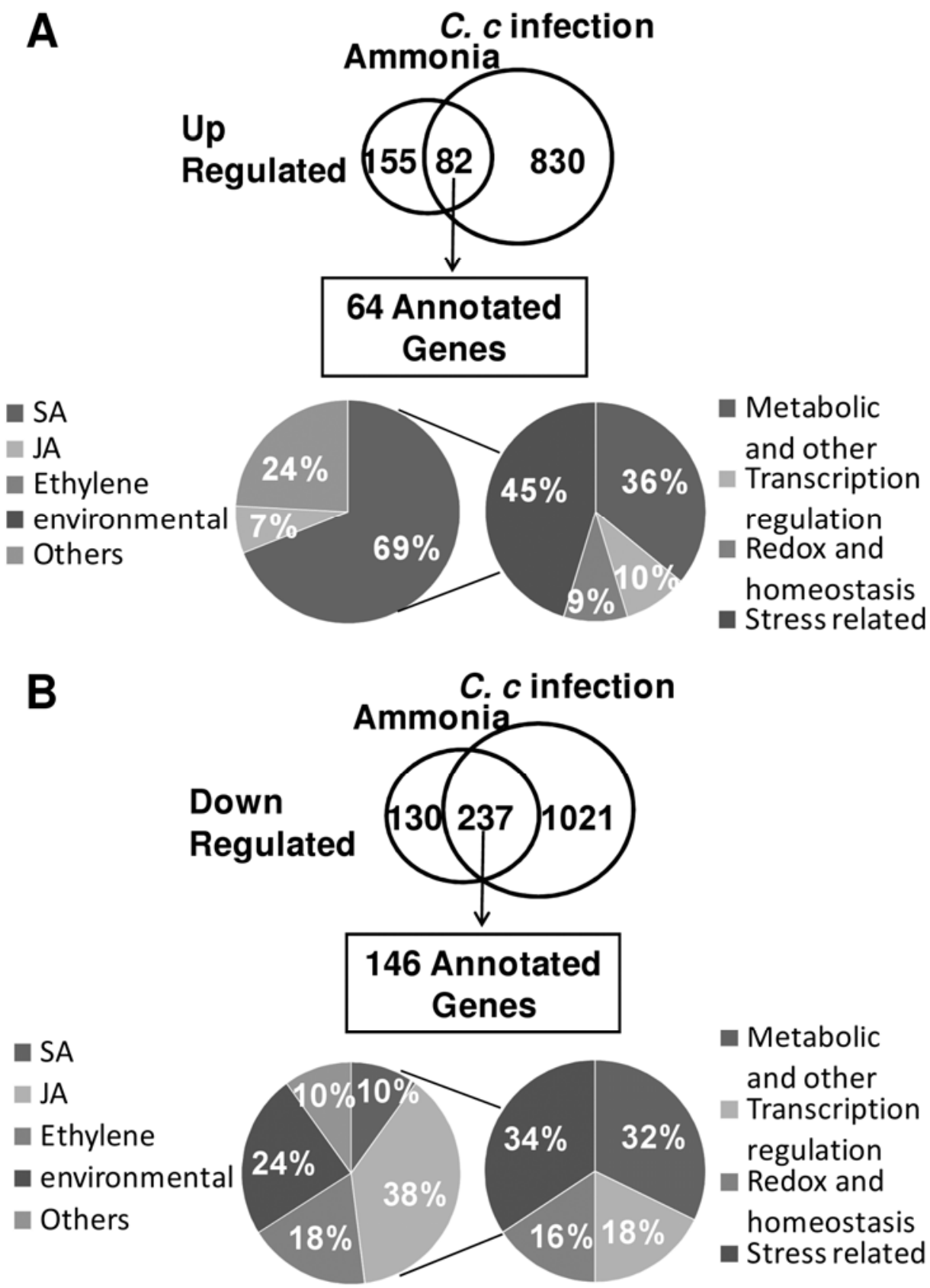

Fig. 2. Overlap between Colletotrichum coccodes and ammonia responsive genes and the distribution of their gene ontology (GO) gene classification. A, Upper diagram shows the expression overlap between upregulated genes in response to ammonium treatment and $C$. coccodes inoculation. Lower diagram shows the group classification of the genes that overlap. B, As in A for the downregulated genes. SA= salicylic acid and JA= jasmonic acid. 
lipase (BM535639) (Ellinger et al. 2010; Turner et al. 2002), and aspartyl protease (AW222400) (Schaller and Ryan 1996). To confirm that the genes chosen were indeed representative of JA- and SA-dependent pathways, the gene expression levels were examined $24 \mathrm{~h}$ after application of $500 \mu \mathrm{M}$ JA or SA to fruit. The results show that, in each case, transcripts were regulated in their expected behavior (Supplementary Table 8).

Analysis of the SA-responsive genes by qRT-PCR indicated that these genes were upregulated in a statistically significant manner 3- to 16-fold in response to $C$. coccodes infection of wild-type (WT) fruit compared with the peeled control, and by 1.76- to 7-fold higher in the ammonium treatment compared with the peeled PBS control (Fig. 3A to C; Supplementary Fig. $\mathrm{S} 3 \mathrm{~A}$ to $\mathrm{C}$ ). The results validate the microarray data, which showed upregulation of 2- to 12.7 -fold in response to infection and upregulation of 1.6- to 2.9-fold in response to ammonium. The expression of these genes was further examined with nit and are $^{-}$mutants of $C$. coccodes. These mutants were previously shown by us to secrete less ammonium and show impaired virulence (Alkan et al. 2008). In each case, the induction of the SA-dependent genes showed a significantly reduced fold increase (up to threefold) when compared with the WT $C$. coccodes infection (Fig. 3A to C).

Analysis of the JA-responsive set of genes by qRT-PCR indicated that $C$. coccodes infection of fruit significantly inhibited the relative expression of this gene set by 4.8 - to 35 -fold compared with the noninoculated wound control, and by 2.0 to 2.2-fold when ammonium treatment was compared with the expression level of its control treatment (Fig. 3D to F). The results are consistent with the microarray data, which showed
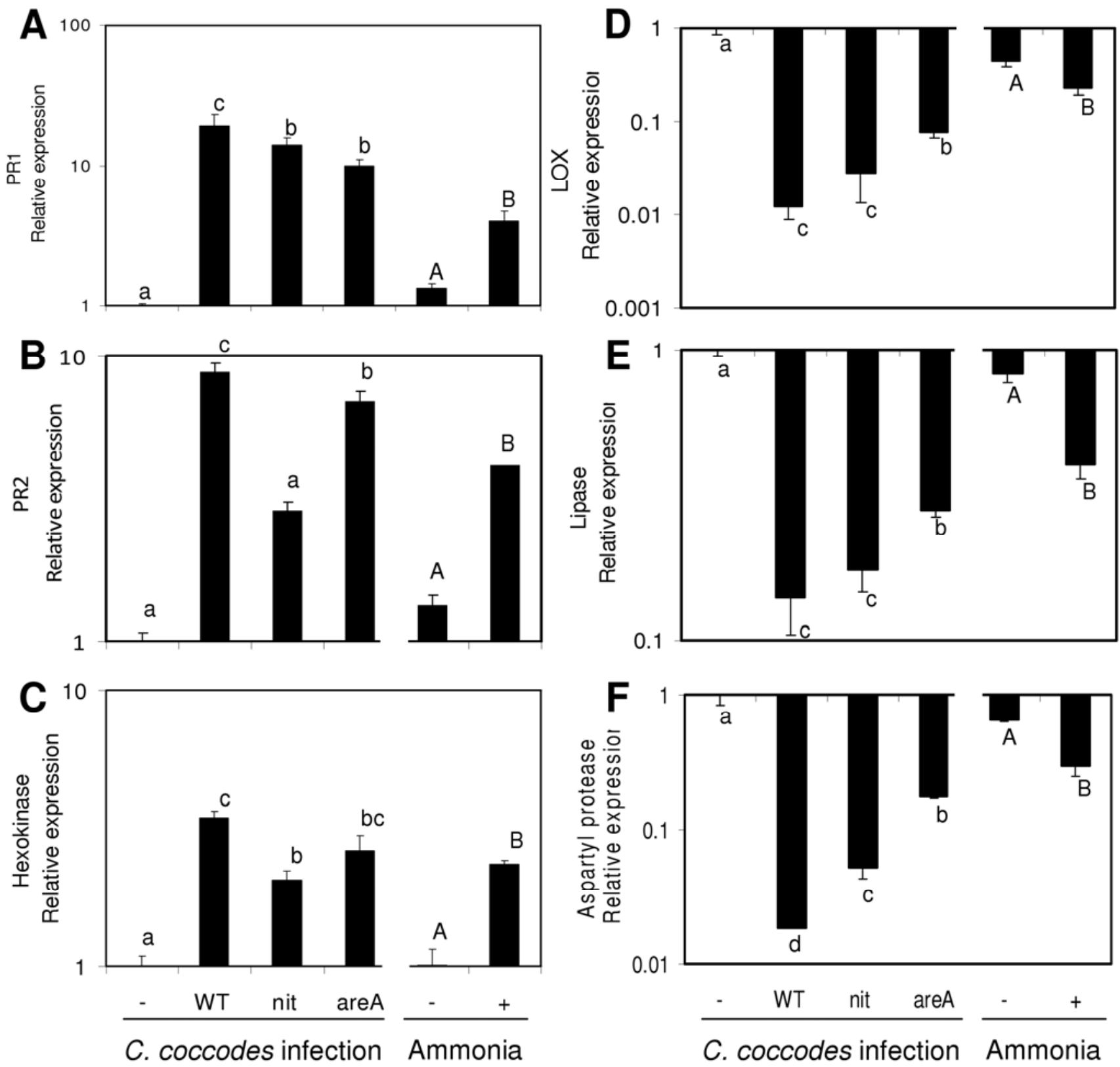

Fig. 3. Relative expression of the select gene set in wild type (WT) and mutant Colletotrichum coccodes 24 h after treatment. Treatments examined are peeled fruit, control, phosphate-buffered saline (PBS), infection of $C$. coccodes $\mathrm{WT}$, nit $1^{-}$, are $A$ mutant, and 5 mM ammonium treatment. Relative expression was normalized to an Actin control. Results shown are relative to the peeled control expression. A, Relative expression of pathogen-related (PR)1. B, Relative expression of PR2 (glucan endo- $\beta$-glucosidase). C, Relative expression of hexokinase. D, Relative expression of lipoxygenase. E, Relative expression of lipase class 3. F, Relative expression of aspartyl protease. Bars are standard error and statistical significance was calculated by analysis of variance and expressed with different letters when $P \leq 0.05$. 
downregulation of 2.7 - to 17 -fold in response to infection and downregulation of 1.8 - to 8.9 -fold in response to ammonium. Infection with mutants of $C$. coccodes, nit, ${ }^{-}$and are $^{-}$, showed up to 10 -fold less repression of these genes when compared with WT $C$. coccodes infection. The expression of these genes in are $^{-}$was reduced in a statistically significant manner compared with the WT, while the expression level of the genes in the nit ${ }^{-}$background were also lower than WT but with variable

Table 1. Effect of ammonium treatment and infection by Colletotrichum coccodes on representative gene expression related to salicylic acid (SA) and jasmonic acid (JA) pathways in green and red tomato

\begin{tabular}{|c|c|c|c|c|c|c|c|}
\hline \multirow[b]{2}{*}{ Treatment $^{\mathrm{a}}$} & \multirow[b]{2}{*}{ Fruit } & \multicolumn{3}{|c|}{ SA dependent } & \multicolumn{3}{|c|}{ JA dependent } \\
\hline & & PR1 & PR2 & Hexokinase & Lipoxygenase & Lipase & Aspartyl protease \\
\hline \multirow[t]{2}{*}{ Infection vs. wound } & Green & 5.5 & 5.5 & 2.0 & -38.3 & -2.0 & -2.8 \\
\hline & Red & $3.0^{*}$ & 3.1 & 2.3 & -34.3 & -1.8 & -3.3 \\
\hline \multirow[t]{2}{*}{ Ammonium vs. PBS } & Green & 1.0 & 2.1 & 2.3 & -2.5 & -1.8 & -2.0 \\
\hline & Red & 1.5 & 4.7 & 2.2 & -2.4 & -1.5 & -1.5 \\
\hline
\end{tabular}

${ }^{a}$ Effects of $C$. coccodes infection on transcript levels are presented by fold change in relative expression after inoculation compared with peeled control in green or red fruit. Ammonium $(5 \mathrm{mM})$ effects are presented by fold change in relative expression after ammonium application compared with phosphatebuffered saline (PBS) peeled control in green or red fruit. All values between green and red fruit for each treatment were found to be the same statistically by Student's $t$ test, except for the case marked by an asterisk. PR = pathogen-related.
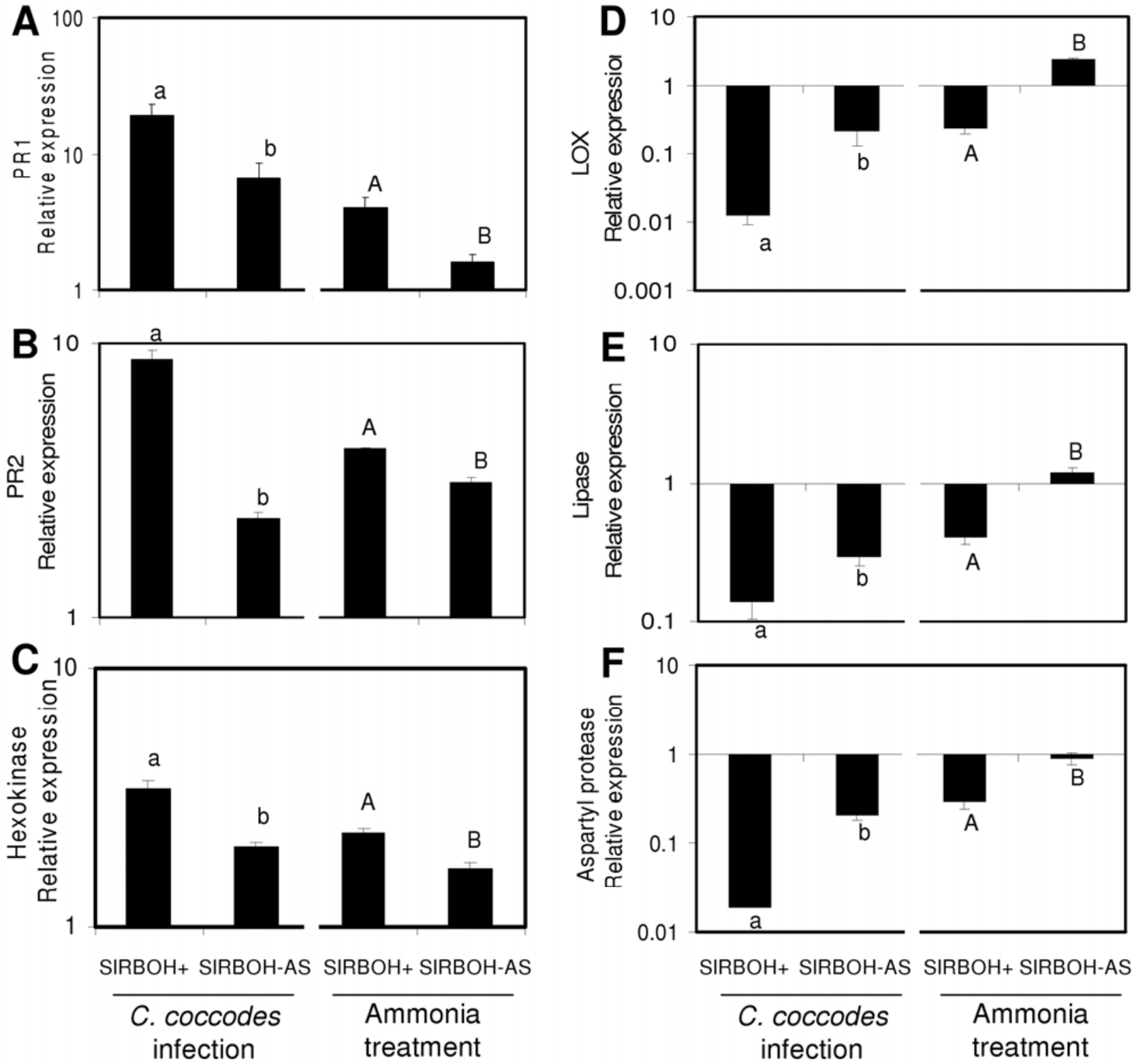

Fig. 4. Relative expression of the select gene set in tomato wild-type (WT) SIRBOH and SIRBOH-AS fruit $24 \mathrm{~h}$ after treatment. WT SIRBOH and SIRBOH-AS fruit were inoculated with Colletotrichum coccodes or treated with $5 \mathrm{mM}$ ammonium. Relative expression was normalized to an Actin control. Results shown are relative to the peeled control expression. A, Relative expression of pathogen-related (PR)1. B, Relative expression of PR2 (glucan endo- $\beta$-glucosidase). C, Relative expression of hexokinase 2. D, Relative expression of lipoxygenase. E, Relative expression of lipase class 3 . F, Relative expression of aspartyl protease. Bars are standard error and statistical significance was calculated by analysis of variance and expressed with different letters when $P \leq 0.05$. 
levels of statistical significance (Fig. 3D to F). Thus, inductions of the select gene set in $C$. coccodes infection and by ammonia confirm the microarray data. In $C$. coccodes mutant infection, the levels of transcript change showed a degree of correlation with the level of ammonia, particularly for SAdependent induction.

\section{Fruit maturation stage and gene responsiveness to ammonium.}

Unripe, mature green tomato fruit are more resistant to postharvest fungal attack than fruit at the breaker stage (Prusky 1996; Treutter 2006; Verhoeff 1974). In "hyphal mat" inoculated fruit, the $\Delta \mathrm{pH}$ at the center of the colonized tissue of both green and red fruit was similar; however, the red fruit was significantly more susceptible than the green fruit, with a fivefold increase in production of ammonia and area colonized (Supplementary Fig. S6). It is possible that resistance of green fruit to infection is determined by differential activation of JA and SA pathways. To examine this, green and red breaker-stage tomato fruit were subjected to ammonium treatments and $C$. coccodes inoculation and the select gene sets were analyzed. Ammonium treatments resulted in the increase of SA-dependent PR1, PR2, and Hexokinase genes of up to 4.7-fold in both green and red fruit (Table 1). C. coccodes infection resulted in a 2- to 5.5-fold increase of SA-representative genes in both green and red fruit (Table 1). Thus, both ammonia and fungal inoculation induced gene expression and, in general, no significant differences in induction levels were found between the green fruit and red fruit (Table 1).

Comparison of the effect on relative expression of JA-dependent pathway transcripts and lipoxygenase, lipase, and aspartyl protease at different fruit maturation stages showed that ammonium application and $C$. coccodes infection induced a decrease in the representative JA-dependent gene expression by 1.5 - to 2.5 -fold and 1.8 - to 38 -fold, respectively, compared with their untreated or uninfected control. In this case as well, there was no significant change in the expression levels of those genes between the green and breaker-

Table 2. Overlap between tomato fruit genes that were upregulated and downregulated by Botrytis cinerea and Colletotrichum coccodes inoculation

\begin{tabular}{|c|c|c|}
\hline Treatments $^{\mathrm{a}}$ & No. of genes & $\mathrm{OF}^{\mathrm{b}}$ \\
\hline \multicolumn{3}{|l|}{ Upregulated } \\
\hline C. coccodes infection & 912 & \\
\hline B. cinerea infection & 99 & \\
\hline Common & 72 & 8.0 \\
\hline \multicolumn{3}{|l|}{ Downregulated } \\
\hline C. coccodes infection & 1,258 & \\
\hline B. cinerea infection & 505 & \\
\hline Common & 199 & 3.1 \\
\hline \multicolumn{3}{|l|}{ Upregulated } \\
\hline $\mathrm{NH}_{4}$ application & 235 & \\
\hline B. cinerea infection & 99 & \\
\hline Common & 11 & 4.7 \\
\hline \multicolumn{3}{|l|}{ Downregulated } \\
\hline $\mathrm{NH}_{4}$ application & 366 & \\
\hline B. cinerea infection & 505 & \\
\hline Common & 83 & 4.5 \\
\hline
\end{tabular}

${ }^{a}$ Microarray data of up- and downregulated genes of tomato red fruit infected by B. cinerea versus wound control compared with the up- and downregulated genes by $C$. coccodes inoculation and ammonia application.

${ }^{\text {b }}$ Overlap representation factor (OF) between the $B$. cinerea and $C$. coccodes inoculation. The statistical significance of all factors is at least $P<0.001$.
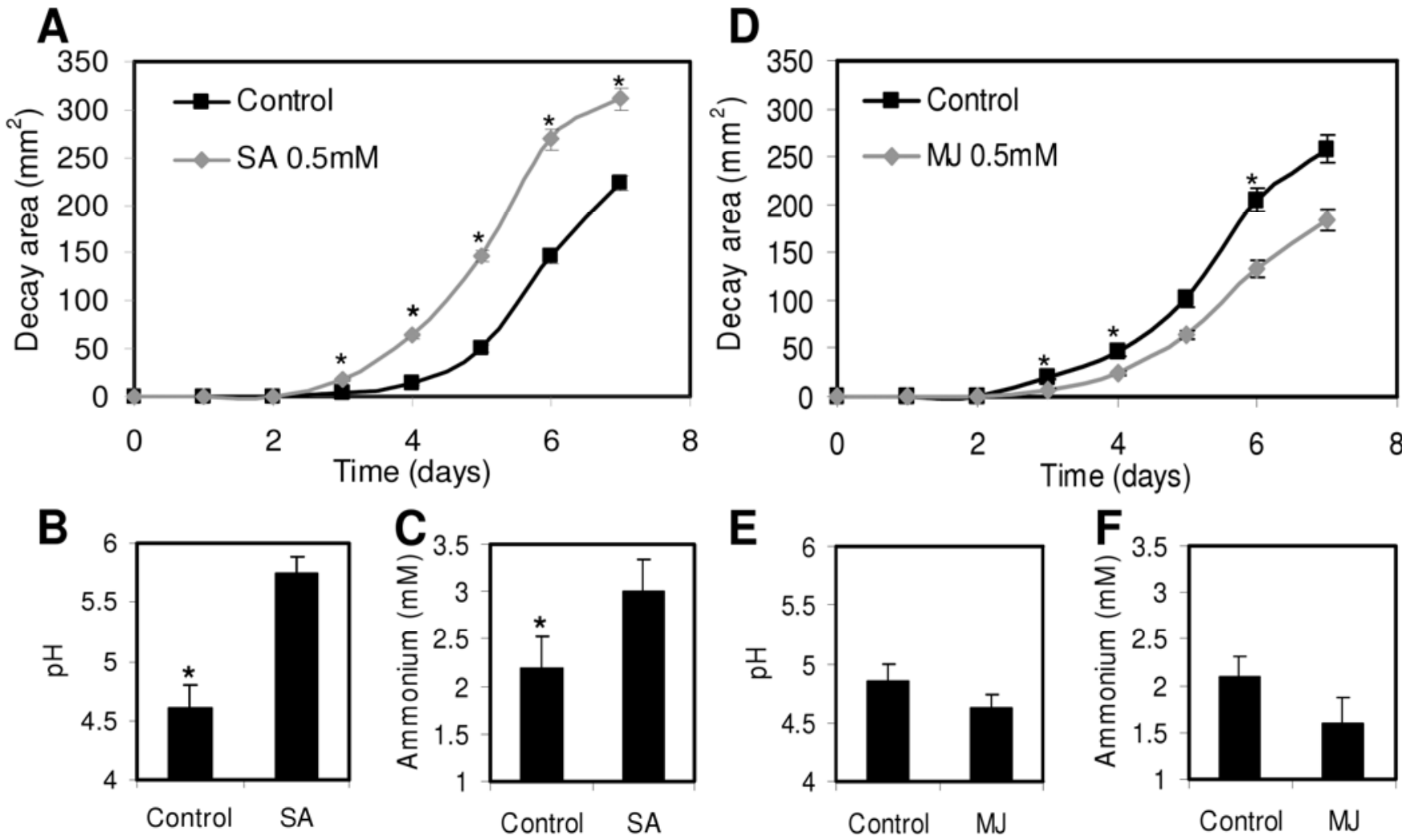

Fig. 5. Effect of salicylic acid (SA) and jasmonic acid (JA) application on the virulence of Colletotrichum coccodes. Virulence is measured by the decay area in square millimeters, production of ammonium in the infection court, or pH change. SA and JA (50 $\mu \mathrm{l}$ of $500 \mu \mathrm{M}$ solution) or double-distilled water (DDW as a control) were injected into tomato fruit $3 \mathrm{~h}$ before inoculation with spores. A, Effect of SA on decay area during 7 days after inoculation; $=$ DDW and $\mathbf{\square}=$ SA. D, Effect of JA on decay area during 7 days after inoculation; $\bullet=$ DDW and $\mathbf{m}=$ JA. B and $\mathbf{E}$, Ammonium concentration at the infection site 2 days postinoculation and treatment with either SA or JA. $\mathbf{C}$ and $\mathbf{F}, \mathrm{pH}$ at the infection site 2 days postinoculation and treatment with either SA or JA. Statistical significance was calculated by analysis of variance and expressed with asterisks when $P \leq 0.05$. 
stage mature fruit in response to ammonium treatment or fungal infection (Table 1).

\section{RBOH-dependent gene induction by ammonium and $C$. coccodes.}

SIRBOH has been previously shown to be responsible for the accumulation of ROS and host cell death (Alkan et al. 2009). It is of interest to examine whether SIRBOH activity is important for the change in JA- and SA-dependent transcripts. RBOH transcript itself is upregulated in response to ammonia treatment and Colletotrichum spp. infection significantly more in the WT tomato than in the SIRBOH-AS line (Supplementary Fig. S4). When ammonia treatments and $C$. coccodes inoculation were carried out on SIRBOH-AS tomato fruit, the SA-pathwaydependent genes showed significant two- to fourfold less expression when compared with the WT SIRBOH fruit response (Fig. 4A to C). Similarly, treatment of the SIRBOH-AS tomato fruit line with ammonia reduced gene expression by 1.3 - to 2.5 -fold compared with the WT SIRBOH fruit (Fig. 4A to C). JA-pathway-dependent genes showed the reciprocal effect. In this case, infection of SIRBOH-AS tomato fruit showed a three- to 17.5fold increase in JA-pathway-dependent gene expression compared with the WT fruit response (i.e., less fold reduction). In response to ammonia treatment, SIRBOH-AS showed a significant increase of 2.1- to 10.4-fold compared with the WT SIRBOH tomato fruit (Fig. 4D to F). Because SIRBOH-AS plants tend to have mild pleiotropic phenotypes (Sagi et al. 2004), two housekeeping genes (actin and tubulin) were monitored and were observed to have similar expression in WT and SIRBOH-AS lines (Supplementary Fig. S5). These results suggest that the modulation of transcripts of SA and JA pathways by ammonia accumulation requires SIRBOH activity.

\section{Hormones affect $C$. coccodes pathogenicity.}

Transcripts induced by SA- and JA-dependent processes were shown here to change during the ammonification process. Therefore, the direct effect of hormones on tomato fruit infection was examined. To this end, tomato fruit were treated with $\mathrm{SA}$ or JA for $3 \mathrm{~h}$ prior to inoculation with spores of $C$. coccodes. The results show that infection sites treated with SA before inoculation showed a significant 2.2-fold increase in decay development 4 days after inoculation (Fig. 5A). This increase in decay development was accompanied with more rapid alkalinization and a 1.5-fold increase in ammonium accumulation when compared with control fruit (Fig. 5B and C). In contrast, preinoculation treatments with JA inhibited decay area compared with the controlled fruit and showed a slightly but significantly smaller decay area by 1.8 -fold 4 days after inoculation (Fig. 5D). JA treatment showed a slower alkalinization rate and lower levels of ammonium concentration than the controlled fruit 2 days postinoculation (Fig. 5E and F).

\section{Ammonium activates host nitrogen metabolism.}

The ammonium-rich infection court present throughout Colletotrichum spp. necrotrophic colonization elicits additional host responses. Inspection of the transcriptome reveals a group of 64 upregulated genes that are found in both ammonium and C. coccodes treatments. Of those, five genes are connected to ammonium fixation: ornithine decarboxylase, which participates in the urea cycle to create putrescine with a high $\mathrm{C}-\mathrm{N}$ ratio; aspartate aminotransferase; branched-chain amino acid aminotransferase; glutamate dehydrogenase (GDH), which transfers amino group to $\alpha$-keto-glutarate; and glutamate decarboxylase, which catalyzes the decarboxylation of glutamate (Supplementary Table 9). The upregulation of those genes could be indicative of a host mechanism that could serve to dissipate local toxic ammonium accumulation by the fungi.

\section{DISCUSSION}

Ammonium activates SA pathways

and suppresses JA pathways leading to host cell death.

The postharvest pathogen Colletotrichum sp. is known to alkalinize its immediate environment by secreting large amounts of ammonium ions. Ammonium plays multiple roles in fungal pathogenicity that include fungal and host targets. In fungi, the $\mathrm{pH}$ shift induced by the accumulating ammonia activates fungal virulence factors at the transcriptional and posttranscriptional level (Drori et al. 2003; Kramer-Haimovich et al. 2006). In mammalians systems, ammonia was found to activate NADPH oxidase in rat astrocytes (Reinehr et al. 2007) and induce autophagy in human cell lines (Eng et al. 2010; Mariño and Kroemer 2010). In tomato fruit, ammonium activates host SIRBOH to generate ROS leading to local host cell death (Alkan et al. 2009). As shown here, transcriptome analysis of tomato tissue inoculated by fungus or by direct ammonia treatment revealed regulation of a common set of genes. The overlap in gene expression in the fruit indicates that ammonia secreted by the fungus plays a significant role in shaping the plant transcriptome responses.

Upregulated genes were found to include a significant enrichment of SA-dependent genes, while the downregulated gene sets were enriched for JA-dependent genes. Hence, in order to further support our suggestion of hormonal control, we analyzed gene expression in fruit after hormone treatment as sensitive indicators of these pathways. Several reports carried out in leaf-fungal interactions have indicated that host response to a biotic stress involve hormones. JA and ethylene pathways have been implicated in necrotrophic interactions and SA pathways in response to biotrophic interactions (Glazebrook 2005; Spoel et al. 2007). In cases where colonization proceeds (e.g., in successful necrotrophic colonization), JA responses were subdued and SA responses and cell death were promoted (Alkan et al. 2009; Cabrera et al. 2006; Colmenares et al. 2002; El-Maarouf et al. 2001; Govrin and Levine 2000; Kim et al. 2008; MacKinnon et al.1999; Matsumura et al. 2003; Otani et al. 1998; Stone et al. 2000). This work extends the paradigm established in leaf-fungus interactions to include the colonization strategy adopted in fungus-fruit interactions as well.

These observations give evidence for contrasting strategies adopted by pathogens with different life styles. In the case of fruit colonization by Colletotrichum spp., a central mechanism by which virulence is accomplished includes the activation of fruit SIRBOH activity by ammonia (Alkan et al. 2009). Our results here extend these observations to show that fruit impaired in SIRBOH expression with reduced ROS production show impaired expression of SA- and JA-dependent genes. Such plants are actually less susceptible to infection, likely due to slower rates of host cell death (this work; Alkan et al. 2009). Other fruit pathogens may operate by a similar mechanism. In C. lagenarium necrotrophic infection of cucumber, the levels of SA and SAR were elevated (Metraux et al. 1990). Pepper fruit responded by rapid PCD induction to $C$. gloeosporioides (Kim et al. 2004). Interestingly, in the case $C$. gloeosporioides infection, applications of SA appear to induce fruit resistance (Lee et al. 2009). However, in that case, SA was added to the early biotrophic phase of infection, which would attenuate infection due to the resultant PCD. In the case of true necrotrophic phase as analyzed here, the addition of SA or initiation of PCD will have the opposite effect.

As shown here, application of JA to fruit pericarp provided a degree of resistance to $C$. coccodes while the addition of SA resulted in acceleration of $C$. coccodes necrotrophic-type colonization. These results are consistent with the observations that the induction of the SA pathway is correlated with tissue PCD. 
Similarly, exogenous JA or methyl jasmonate (MeJA) application to leaves induced resistance against the necrotrophs Alternaria brassicicola, Botrytis cinerea, and Phytophthora infestans (Cohen et al. 1993; Thomma et al. 1998, 2000; Ton et al. 2002). Furthermore, in tomato, the JA-pathway mutant defl exhibited increased susceptibility to Fusarium oxysporum, Pseudomonas syringae, Phytophthora infestans, and Verticillium dahliae (Thaler et al. 2004). A mechanism in which ammonium activates the SA-dependent pathway and, thus, effects host susceptibility which facilitates further fungal colonization and, hence, increased ammonium accumulation is self sustained.

\section{Host responses to infection and ammonia treatment in different stages of fruit maturation are similar.}

C. coccodes conidia can breach the unripe fruit cuticle in the field and then remain quiescent for months until fruit are ripe to harvest (Prusky 1996; Prusky and Lichter 2007). Unripe fruit are considered to be resistant to postharvest pathogens and one may expect that both physiological stages will react differently to fungal attack (Prusky 1996). However, the results here indicate that green and red fruit activate similar pathways in response to ammonium and $C$. coccodes infection, as detected by induction of specific transcripts (Table 1). These results suggest that the host response involving SA and JA modulation is similar for the green stage and red breaker-stage. Thus, the state of fungal quiescence achieved in immature fruit is not related to differential activation of these pathways.

Several alternative hypotheses to explain the quiescence of pathogens in unripe fruit and their transition to necrotrophic life style during fruit ripening have been offered. Resistance in immature fruit could arise from the presence of preformed antifungal compounds that subsequently decrease during ripening. For example, in tomato fruit, the amounts of tomatine and saponine, potent antifungal compounds, were shown to decrease as the fruit ripens (De-Fago et al. 1983; Osbourn 1996). Unsuitable ambient $\mathrm{pH}$ may also contribute to the resistance of unripe fruit because extracellular $\mathrm{pH}$ of tomato fruit was shown to decrease from 6.7 to 4.4 during fruit ripening (Almeida and Huber 1999). It has been suggested that enhanced acidity possibly activates $C$. coccodes ammonium secretion (Alkan et al. 2008). Thus, the local reactions that occur during initial fungal ingress into the immature fruit in the context of higher tomatine, saponine, and extracellular $\mathrm{pH}$ will signal the fungus to enter into the quiescence-type stage; whereas, in mature red fruit, the reduced amounts of preformed antifungal compounds and lower host $\mathrm{pH}$ will signal the fungus to enter into necrotrophic-type colonization.

\section{Commonalties and differences in necrotrophic strategies between fungi with divergent life styles.}

In contrast to the alkalinization of the infection court by $C$. coccodes, $B$. cinerea tends to acidify its surroundings. Therefore, it is of interest to compare plant responses to these different pathogens that both infect the tomato fruit. Transcriptome analysis of ripe tomato fruit in response to necrotrophic attack of B. cinerea was recently published (Cantu et al. 2009). Evaluation of the tomato red fruit response to $B$. cinerea revealed 99 upregulated genes and 505 downregulated genes compared with its own wound control (Cantu et al. 2009). Comparison of those gene sets to responses in $C$. coccodes infection revealed highly significant, 72 and 199 common, up- and downregulated genes, respectively (Table 2). In contrast, comparison of the responses to ammonia application as measured here revealed much less overlap (11 upregulated genes and 83 downregulated genes). Thus, the gene sets held in common may be a reflection of common plant responses to necrotrophic attack. In contrast, the lack of overlap with ammonia may reflect the very different colonization strategy. $C$. coccodes alkalinizes the environment with ammonia whereas, in $B$. cinerea, secretion of oxalic acid leads to acidification (Gentile 1954; Manteau et al. 2003).

\section{Ammonium activates host nitrogen metabolism.}

Inspection of the transcriptome reveals additional host response: a group of five genes are connected to ammonium fixation out of 64 upregulated genes that are found in both ammonium and $C$. coccodes treatments. The upregulation of those genes could be indicative of a host mechanism that could serve to dissipate local toxic ammonium accumulation by the fungi. However, it is unlikely that metabolic flux through these pathways plays a positive role in fruit survival and it may indicate further insidious abuse by the pathogen. For example, among the induced genes, ornithine decarboxylase has been described previously as an inducer of PCD (Negrel et al. 1984; Packham and Cleveland 1994; Walters 2003; Yoda et al. 2003). Aspartate aminotransferase was upregulated in apoptotic Arabidopsis tissue (Gechev et al. 2004) and was described as a marker for PCD and senescence (Yoshida et al. 2001). Branched-chain amino acid aminotransferase seemed to have a key role in mammalian apoptosis (Eden and Benvenisty 1999). Glutamate decarboxylase has a major role in controlling GABA, stress response, and plant PCD (Bouché et al. 2004; Takahashi et al. 2008). In mammalian systems, GDH antagonized the inhibition of caspase in late apoptosis and accelerated PCD (Verhagen et al. 2007). In plants, GDH serves as a senescence-related marker and is related to cell death (Pageau et al. 2006). Its transcription was activated during necrotrophic infection by Phoma macdonaldii, B. cinerea, C. gloeosporioides, and C. lindemuthianum and by fungal elicitors (Alignan et al. 2006; Dulermo et al. 2009; Pageau et al. 2006; Tavernier et al. 2007). Thus, the function of these transcript changes may go beyond the simple removal of ammonia, which would be to the plant's benefit, and may serve as a role in accelerating host cell death for the benefit of the necrotrophic colonization by the fungus.

\section{Conclusions.}

The switch in fungal lifestyle from the quiescent stage to necrotrophic growth is a major concern in postharvest fruit. This work further demonstrates that $C$. coccodes uses ammonium secretion as a novel dual-edged strategy for fungal colonization of ripening fruit. Ammonia optimizes the $\mathrm{pH}$ of the infection court to make it conducive to activation of fungal virulence genes and, at the same time, activates host $\mathrm{RBOH}$ that apparently stimulates SA pathway responses and suppresses JA pathway responses. Those processes correlate with local cell death, enhance the aggressiveness of $C$. coccodes during its necrotrophic stage, and increase ammonium accumulation in a cycle of pathogenicity. Our results also suggest that the switch from quiescence in green fruit to active infection in red fruit is not due to a breakdown of induced host response because this response is similar in the different fruit maturation stages. It is possible that the changing context of the maturing tissue, such as pH changes (Prusky and Yakoby 2003) or the presence of preformed antifungal agents (De-Fago et al. 1983; Osbourn 1996) contribute to the choice of fungal lifestyle.

\section{MATERIALS AND METHODS}

Plant material, fungal strains, media, and growth conditions.

For microarray analysis and functional analysis, Solanum lycopersicum 'Hazera 1402' (susceptible to C. coccodes) grown in a greenhouse was used. All the other experiments were preformed on $S$. lycopersicum 'Motelle.' WT and transgenic plants expressing SIRBOH (AAD25300) and Wfil (AF73124) 
fragments in sense and antisense orientation, respectively, were used to obtain SIRBOH-AS line 9 and line 12. The lines were used at the M3 stage and are independent isolates of lines described by Sagi and associates (2004). The plants were grown in pots filled with a peat-vermiculite $(4: 1$, vol/vol $) \mathrm{mix}$ ture containing slow-release high-N Multicote 4 with microelements (0.3\% wt/wt; Haifa Chemicals, Haifa Bay, Israel). Average temperatures in the greenhouse during the growth period fluctuated from 18 to $25^{\circ} \mathrm{C}$.

C. coccodes isolate 138 , pathogenic on tomato fruit, was obtained from decayed potato tubers in Israel (supplied by L. Tzror, Agricultural Research Organization) (Nitzan et al. 2002). Single-spore cultures were maintained routinely on Mathur's medium (Tu 1985). Spores of the original singlespore culture were maintained in $40 \%$ glycerol at $-80^{\circ} \mathrm{C}$ as a source of inoculum. $C$. coccodes nit $1^{-}$mutant was generated in the presence of potassium chlorate (Alkan et al. 2008). C. coccodes are $A^{-}$(strains 787 and 757) mutant lines were obtained by direct hygromycin cassette insertion using the Gateway system as described by Alkan and associates (2008).

\section{Fruit inoculation, fruit treatments, and infection parameters.}

For inoculation with fungal hyphae, freshly harvested mature breaker-stage tomato fruit of the same age and size $(S$. $l y$ copersicum 'Hazera 1402' or S. lycopersicum 'Motelle' WT and SIRBOH-AS line 9 and line 12) were used for inoculations. The fruit were surface sterilized in $0.3 \%$ ( $\mathrm{vol} / \mathrm{vol})$ hypochlorite for $10 \mathrm{~min}$, rinsed thoroughly with water, and dried. Fruit inoculation was carried out on the pericarp. A section of peel tissue $0.2 \mathrm{~mm}$ thick and $10 \mathrm{~mm}$ in diameter was removed from the tomato fruit and replaced by a 0.2 -mm-thick hyphal mat of $C$. coccodes mycelia showing different levels of ammonium secretion as WT, nit1- (nitrate reductase), and are $^{-}$mutants (major nitrogen regulation factor) (Alkan et al. 2008). This hyphal mat was obtained by growing spores for 3 days on primary media and transferred for 1 day of growth on secondary media ("hyphal mat infection method") (Alkan et al. 2008). For ammonium and PBS treatments, $50 \mu \mathrm{l}$ of $5 \mathrm{mM}$ ammonium chloride in PBS buffer or PBS buffer as a control was pipetted directly on the wounded tissue every $5 \mathrm{~h}$. PBS buffer is 137 $\mathrm{mM} \mathrm{NaCl}, 2.7 \mathrm{mM} \mathrm{KCl}, 10 \mathrm{mM}$ sodium phosphate dibasic, 2 $\mathrm{mM}$ potassium phosphate monobasic, and a $\mathrm{pH}$ of 7.4. Following inoculation or treatments, fruit were incubated at $22^{\circ} \mathrm{C}$ and $95 \%$ relative humidity $(\mathrm{RH})$ in covered plastic containers containing wet paper towels. Each treatment had three biological repeats and each biological repeat consisted of four inoculations or treatments per fruit on five different fruit (20 inoculation replicates). The samples were collected $24 \mathrm{~h}$ postinfection or treatment.

To test the effect of SA and JA on fungal colonization, the tomato fruit pericarp was injected at a $1-\mathrm{mm}$ depth with $50 \mu \mathrm{l}$ of $0 \mu \mathrm{M}, 100 \mu \mathrm{M}, 500 \mu \mathrm{M}$, or $1 \mathrm{mM}$ MeJA (Meir et al. 2005) or SA $3 \mathrm{~h}$ prior to $C$. coccodes spores inoculation. All the examined concentration showed similar expression patterns, and treatments with $500 \mu \mathrm{M}$ SA or MeJA were sufficient to modulate host response. Three hours later, $10 \mu \mathrm{l}$ of $C$. coccodes at $10^{5} \mathrm{spore} / \mathrm{ml}$ was wound inoculated to the same site. Following inoculation, fruit were incubated at $22^{\circ} \mathrm{C}$ and $95 \%$ $\mathrm{RH}$ in covered plastic containers containing wet paper towels. Each treatment consisted of 3 inoculations per fruit on 15 different fruit (i.e., 45 inoculation replicates). Disease evaluation of inoculated tomato fruit included measurements of i) decay area (square millimeters), measured during 7 days postinoculation; ii) ammonium levels, tested by an ammonium test kit (Merck, Darmstadt, Germany) $48 \mathrm{~h}$ postinoculation; and iii) $\mathrm{pH}$, monitored by a 3-mm double-pure piercing electrode (EU-
TECH Instruments, Zurich) $48 \mathrm{~h}$ postinoculation. For measurements of gene induction by SA and JA, fruit were examined $24 \mathrm{~h}$ after JA, SA, or control treatments. For qRT-PCR analysis, three biological repeats for each treatment were collected (each biological repeat consisted of four inoculations).

\section{RNA isolation.}

Total RNA was prepared from the fruit pericarp, where each biological repeat consisted of 20 infections or treatments of 10 $\mathrm{mm}$ in diameter and 3 to $4 \mathrm{~mm}$ deep from at least five different fruit. For RNA isolation, $1 \mathrm{~g}$ of tissue was ground in liquid nitrogen, transferred to $4 \mathrm{ml}$ of extraction buffer $(100 \mathrm{mM}$ Tris- $\mathrm{HCl}$ at $\mathrm{pH} 9.0,200 \mathrm{mM} \mathrm{NaCl}, 15 \mathrm{mM}$ EDTA at $\mathrm{pH} 8.0$, and $0.5 \%$ sarkosyl) and homogenized; then, $4 \mathrm{ml}$ of phenol and $280 \mu \mathrm{l}$ of $3 \mathrm{M}$ sodium acetate were added and the mixture was homogenized. The extraction was subjected to $10 \mathrm{~min}$ of centrifuging at $10,000 \mathrm{rpm}$ and $4 \mathrm{ml}$ of Tri-reagent (SigmaAldrich, St. Louis) was added to the supernatant, mixed, and centrifuged as above. Isopropanol was added to the supernatant and the mixture was kept on ice for an hour and then centrifuged as above. The pellet was resuspended in $1 \mathrm{ml}$ of water. The water had been pretreated with $0.1 \%$ diethyl dicarbonate for $1 \mathrm{~h}$ at $37^{\circ} \mathrm{C}$ and then autoclaved. The dissolved nucleic acids were mixed with $0.5 \mathrm{ml}$ of $8 \mathrm{~N} \mathrm{LiCl}$ and kept on ice overnight. The mixture was centrifuged as above and the pellet was washed with $70 \%$ ethanol and dried. The RNA pellet was treated with DNase (Turbo-DNA Free; Ambion, Austin, TX, U.S.A.) followed by RNA cleanup with the RNAeasy plant mini kit (Qiagen, Hilden, Germany). The RNA concentration and purity were measured using a NanoDrop 1000 spectrophotometer (Thermo Scientific, Wilmington, DE, U.S.A.). RNA integrity was checked by agarose gel electrophoresis.

\section{Microarray analysis.}

Total RNA $(10 \mu \mathrm{g})$ was processed for the microarray hybridizations using the Affymetrix GeneChip one-cycle target-labeling kit (Affymetrix, Santa Clara, CA, U.S.A.). The two treatments were $C$. coccodes hyphal mat inoculation compared with a wound control ( $24 \mathrm{~h}$ after the tomato fruit peel was removed) and $5 \mathrm{mM}$ ammonium treatment in PBS, as described previously, compared with PBS wound control. Each treatment was performed in two independent biological replicates. The biotinylated complementary RNA was fragmented and hybridized to the GeneChip Tomato genome array (10,038 tomato probe sets for more than 9,200 tomato genes). The arrays were washed, stained, and scanned at the Biological Services at the Weizmann Institute (Rehovot, Israel).

CEL files for the Affymetrix microarray data arising from the microarray experiments were analyzed utilizing the Partek Genomics software (Downey 2006). The processing of the data included quantile normalization using the robust multiarray analysis (RMA) algorithm (Irizarry et al. 2003) and a one-way standard analysis of variance (ANOVA) model. The probability value ( $P$ value) was corrected with the BenjaminiHochberg FDR technique for multiple test comparisons (Benjamini and Hochberg 1995). FDR $<0.05$ was considered significant. The threshold values were 1.5 -fold changes. The consistency of the replication was confirmed by hierarchical clustering based on RMA. All the slides showed similar average and standard deviations. The data was submitted to GEO, accession number GSE21999. GO annotation was obtained using Blast2GO software (Conesa et al. 2005) using default parameters against the Arabidopsis database.

\section{Statistical analysis.}

The statistical significance of gene expression overlaps was calculated using representation fold factor that represents the 
number of overlapping genes divided by the expected number of overlapping genes drawn from two independent groups. The possibility that these factors are a random event was calculated by hypergeometric probability. A representation factor $>1$ indicates more overlap than expected. For statistical overrepresentation of groups of genes, a probability test and $\chi^{2}$ test were used by measuring the statistical overrepresentation of specific term in the GO annotation compared with all the genes in the array. Parametric analysis of gene set enrichment analysis was also conducted using the Easy Go software to reveal overrepresentation of up- and downregulated groups of genes (Zhou and $\mathrm{Su}$ 2007). The statistical differences between the treatment average results from qRT-PCR were checked for significance by ANOVA using the Tukey test. For significance of decay area differences after hormone application, a $t$ test was used.

\section{Quantitative real time PCR analysis.}

RNA was extracted (described above) and a reverse-transcription reaction was performed on $1 \mu \mathrm{g}$ of total RNA with the Reverse-It first-strand synthesis kit (ABgene, Surrey, U.K.). Samples of cDNA were diluted 1:10 ( $\mathrm{vol} / \mathrm{vol}$ ) before carrying out real-time qRT-PCR. The reaction was performed with the RotorGene 3000 (Corbett Research, Sydney, Australia). PCR amplification was composed of $3.4 \mu \mathrm{l}$ of cDNA templates in $10 \mu \mathrm{l}$ of a reaction mixture containing $5 \mu \mathrm{l}$ of Syber-Green amplification mix (ABgene) and $300 \mathrm{nM}$ primers. PCR conditions were: initial denaturation for $15 \mathrm{~min}$ at $94^{\circ} \mathrm{C}$ and $40 \mathrm{de}-$ naturation cycles of $10 \mathrm{~s}$ at $94^{\circ} \mathrm{C}$, annealing at $60^{\circ} \mathrm{C}$ for $15 \mathrm{~s}$, and extension at $72^{\circ} \mathrm{C}$ for $20 \mathrm{~s}$. For qRT-PCR, the samples were subjected to melting-curve analysis with the RotorGene program. All samples were normalized to the Actin gene whose expression did not change in the microarray analysis. The forward and reverse primers for all the genes are summarized in Supplementary Table 7. Each treatment had three biological repeats with three replicates. Averages of biological repeats are presented with the standard error.

\section{Terminal deoxynucleotidyl TUNEL and DAPI staining.}

Apoptosis was determined on S. lycopersicum 'Motelle' WT leaves infiltrated with PBS or with $20 \mathrm{mM}$ ammonia-chloride in PBS. The leaves were incubated at $22^{\circ} \mathrm{C}$ and $95 \% \mathrm{RH}$ in covered plastic containers containing wet paper towels for $24 \mathrm{~h}$. The tomato leaves were cut to $10 \mathrm{~mm}$ in diameter, were fixed with FAA (4\% formaldehyde, 5\% acetic acid, 50\% ethanol), and were embedded in paraffin (Ruzin 1999). The paraffin-embedded tomato leaves were cut into $15-\mu \mathrm{m}$ slices with the microtome. The slides were rehydrated with xylene and decreasing ethanol percentage $(100,95,70,30$, and $0 \%)$, followed by the TUNEL manufacturer instructions assay using the In Situ cell death detection kit fluorescein (Roche Diagnostics, Mannheim, Germany) and were counterstained for $10 \mathrm{~min}$ in $600 \mathrm{nM}$ DAPI and rinsed twice with PBS. The slides were observed with a fluorescence microscope (Leica DM LB 100S) under UV light for DAPI staining or 495-nm excision and 520-nm emission for TUNEL detection.

Tomato fruit parenchymal tissues were manually cut to 300 $\mu \mathrm{m}$ deep and the slides were rinsed with PBS, incubated for 10 min in $600 \mathrm{nM}$ DAPI, and rinsed twice with PBS. Preparations were scanned with a laser-scanning confocal microscope (Olympus IX81). The detection of a DNA fractionation pattern was carried out in S. lycopersicum 'Motelle' WT early breaker fruit treated with PBS or with $20 \mathrm{mM}$ ammonia-chloride in PBS. The fruit were incubated at $22^{\circ} \mathrm{C}$ and $95 \% \mathrm{RH}$ in covered plastic containers containing wet paper towels for $24 \mathrm{~h}$. DNA was extracted from $200 \mathrm{mg}$ of treated parenchymal fruit tissue using the sodium dodecyl sulfate-based protocol followed by RNase treatment (Turci et al. 2010). The DNA size and frac- tionation were determined on $300 \mathrm{ng}$ of total DNA loaded onto $0.8 \%$ (wt/vol) agarose gel and separated by electrophoresis in $1 \times$ Tris-acetate-EDTA buffer.

\section{ACKNOWLEDGMENTS}

This work was supported by U.S.-Israel Binational Agricultural Research and Development Fund (research grant number IS-3945-06). We thank H. Zemach for her help with histology and N. Leviatan and D. Volodarsky for their help in microarray analysis.

\section{LITERATURE CITED}

Alignan, M., Hewezi, T., Petitprez, M., Dechamp-Guillaume, G., and Gentzbittel, L. 2006. A cDNA microarray approach to decipher sunflower (Helianthus annuus) responses to the necrotrophic fungus Phoma macdonaldii. New Phytol. 170:523-536.

Alkan, N., Fluhr, R., Sherman, A., and Prusky, D. 2008. Role of ammonia secretion and $\mathrm{pH}$ modulation on pathogenicity of Colletotrichum coccodes on tomato fruit. Mol. Plant-Microbe Interact. 21:1058-1066.

Alkan, N., Fluhr, R., Sagi, M., Davydov, O., and Prusky, D. 2009. Ammonium secretion by Colletotrichum coccodes activates host NADPH oxidase activity enhancing host cell death and fungal virulence in tomato fruits. Mol. Plant-Microbe Interact. 22:1484-1491.

Almeida, D. P. F., and Huber, D. J. 1999. Apoplastic pH and inorganic ion levels in tomato fruit: A potential means for regulation of cell wall metabolism during ripening. Physiol. Plant. 105:506-512.

Benjamini, Y., Hochberg, Y. 1995. Controlling the false discovery rate: A practical and powerful approach to multiple testing. J. R. Stat. Soc. Ser. B. 57:289-300.

Bouché, N., Fait, A., Zik, M., and Fromm, H. 2004. The root specific glutamate decarboxylase (GAD1) is essential for sustaining GABA levels in Arabidopsis. Plant Mol. Biol. 55:315-325.

Britto, D. T., and Kronzucker, H. J. 2002. $\mathrm{NH}_{4}{ }^{+}$toxicity in higher plants: A critical review. J. Plant Physiol. 159:567-584.

Cabrera, J. C., Messiaen, J., Cambier, P., and Van Cutsem, P. 2006. Size, acetylation and concentration of chitooligosaccharide elicitors determine the switch from defence involving PAL activation to cell death and water peroxide production in Arabidopsis cell suspensions. Physiol. Plant. 127:44-56.

Cantu, D., Blanco-Ulate, B., Yang, L., Labavitch, M. J., Bennett, A. B., and Powell, A. L. T. 2009. Ripening-regulated susceptibility of tomato fruit to Botrytis cinerea requires NOR but not RIN or ethylene. Plant Physiol. 150:1434-1449.

Cohen, Y., Gisi, U., and Niderman, T. 1993. Local and systemic protection against Phytophthora infestans induced in potato and tomato plants by jasmonic acid and jasmonic methyl ester. Phytopathology 83:1054-1062.

Colmenares, A. J., Aleu, J., Duran-Patron, R., Collado, I. G., and HernandezGalan, R. 2002. The putative role of botrydial and related metabolites in the infection mechanism of Botrytis cinerea. J. Chem. Ecol. 28:997-1005.

Conesa, A., Gotz, S., Garcia-Gomez, J. M., Terol, J., Talon, M., and Robles, M. 2005. Blast2GO: A universal tool for annotation, visualization and analysis in functional genomics research. Bioinformatics. 21:3674-3676

Davis, J. M., Wu, H., Cooke, J. E. K., Reed, J., Luce, K. S., and Michler, C. H. 2002. Pathogen challenge, salicylic acid and jasmonic acid regulate expression of chitinase gene homologs in pine. Mol. Plant-Microbe Interact. 15:380-387.

De-Fago, G., Kern, H., and Sedlar, L. 1983. Genetic analysis of tomatin insensitivity, sterol content and pathogeniciy for green tomato fruits in mutants of Fusarium solani. Physiol. Plant Pathol. 22:39-43.

De-León, P. I., Oliver, J. P., Castro, A., Gaggero, C., Bentancor, M., and Vidal, S. 2007. Erwinia carotovora elicitors and Botrytis cinerea activate defense responses in Physcomitrella patens. BMC Plant Biol. 7:52.

Downey, T. 2006. Analysis of a multifactor microarray study using Partek genomics solution. Methods Enzymol. 411:256-270.

Drori, N., Kramer-Haimovich, H., Rollins, J., Dinoor, A., Okon, Y., Pines, O., and Prusky, D. 2003. A combination of external $\mathrm{pH}$ and nitrogen assimilation affect secretion of the virulence factor pectate lyase by $C$. gloeosporioides. Appl. Environ. Microbiol. 69:3258-3262.

Duan, Y., Zhang, W., Bao, L., Wang, Y., Li, K., Han, C., Zhang, Y., and Li, X. 2010. An endoplasmic reticulum response pathway mediates programmed cell death of root tip induced by water stress in Arabidopsis. New Physiol. 186:681-695.

Dulermo, T., Bligny, R., Gout, E., and Cotton, P. 2009. Amino acid changes during sunflower infection by the necrotrophic fungus $B$. cinerea. Plant Signal. Behav. 4:859-861.

Eden, A., and Benvenisty, N. 1999. Involvement of branched-chain amino 
acid aminotransferase (Bcat1/Eca39) in apoptosis. FEBS (Feb. Eur. Biochem. Soc.) Lett. 27:255-261.

El-Maarouf, H., Barny, M. A., Rona, J. P., and Bouteau, F. 2001. Harpin, a hypersensitive response elicitor from Erwinia amylovora, regulates ion channel activities in Arabidopsis thaliana suspension cells. FEBS (Feb. Eur. Biochem. Soc.) Lett. 497:82-84.

Ellinger, D., Stingl, N., Ingeborg-Kubigsteltig, I., Bals, T., Juenger, M., Pollmann, S., Berger, S., Schuenemann, D., and Mueller, M. J. 2010. Dongle and defective in anther dehiscencel lipases are not essential for wound- and pathogen-induced jasmonate biosynthesis: Redundant lipases contribute to jasmonate formation. Plant Physiol. 153:114-127.

Eng, C. H., Yu, H. K., Lucas. J., White, E., and Abraham, R. T. 2010. Ammonia derived from glutaminolysis is a diffusible regulator of autophagy. Sci. Signal. 119:ra31.

Enyedi., A. J., and Raskin, I. 1993. Induction of UDP-glucose salicylic acid glucosyltransferase activity in tobacco mosaic virus inoculated tobacco (Nicotiana tabacom) leaves. Plant Physiol. 101:1375-1380.

Eshel, D., Miyara, I., Ailinng, T., Dinoor, A., and Prusky, D. 2002. pH regulates endoglucanase expression and virulence of Alternaria alternata in persimmon fruits. Mol. Plant-Microbe Interact. 15:774-779.

Ge, X., Dietrich, C., Matsuno, M., Li, G., Berg, H., and Xia, Y. 2005. An Arabidopsis aspartic protease functions as an anti-cell death component in reproduction and embryogenesis. EMBO (Eur. Mol. Biol. Organ.) Rep. 6:282-288

Gechev, T. S., Gadjev, I. Z., and Hille, J. 2004. An extensive microarray analysis of AAL-toxin-induced cell death in Arabidopsis thaliana brings new insights into the complexity of programmed cell death in plants. Cell. Mol. Life Sci. 61:1185-1197.

Gentile, A. C. 1954. Carbohydrate metabolism and oxalic acid synthesis by Botrytis cinerea. Plant Physiol. 29:257-261.

Glazebrook, J. 2005. Contrasting mechanisms of defense against biotrophic and necrotrophic pathogens. Annu. Rev. Phytopathol. 43:205-227.

Govrin, E. M., and Levine, A. 2000. The hypersensitive response facilitates plant infection by the necrotrophic pathogen Botrytis cinerea. Curr. Biol. 10:751-757.

Gu, Y. Q., Wildermuth, M. C., Chakravarthy, S., Loh, Y. T., Yang, C., He, X., Han, Y., and Martin, G. B. 2002. Tomato transcription factors Pti4, Pti5, and Pti6 activate defense responses when expressed in Arabidopsis. Plant Cell 14:817-831.

Gunawardena, A. H. L. A. N, Greenwood, J. S., and Dengler, N. G. 2004. Programmed cell death remodels lace plant leaf shape during development. Plant Cell 16:60-73.

Hadas, Y., Goldberg, I., Pines, O., and Prusky, D. 2007. Involvement of gluconic acid and glucose oxidase in the pathogenicity of Penicillium expansum in apples. Phytopathology 97:384-390.

Heitz, T., Bergey, D. R., and Ryan, C. A. 1997. A gene encoding a chloroplast-targeted lipoxygenase in tomato leaves is transiently induced by wounding, systemin, and methyl jasmonate. Plant Physiol. 114:10851093.

Irizarry, R. A., Bolstad, B. M., Collin, F., Cope, L. M., Hobbs, B., and Speed, T. P. 2003. Summaries of Affymetrix GeneChip probe level data. Nucleic Acids Res. 31:1-8.

Keller, H., Bonnet, P., Galiana, E., Pruvot, L., Friedrich, L., Ryals, J., and Ricci, P. 1996. Salicylic acid mediates elicitin-induced systemic acquired resistance, but not necrosis in tobacco. Mol. Plant-Microbe Interact. 9:696-703.

Kim, K. H., Yoon, J. B., Park, H. G., Park, E. W., and Kim, Y. H. 2004. Structural modifications and programmed cell death of chili pepper fruit related to resistance responses to Colletotrichum gloeosporioides infection. Phytopathology 94:1295-130.

Kim, K. S., Min, J. Y., and Dickman, M. B. 2008. Oxalic acid is an elicitor of plant programmed cell death during Sclerotinia sclerotiorum disease development. Mol. Plant-Microbe Interact. 21:605-612.

Kim, M., Lim, J. H., Ahn, C. S., Park, K., Kim, G. T., Kim, W. T., and Pai, H. S. 2006. Mitochondria-associated hexokinases play a role in the control of programmed cell death in Nicotiana benthamiana. Plant Cell $18: 2341-2355$

Kramer-Haimovich, H., Servi, E., Katan, T., Rollins, J., Okon, Y., and Prusky, D. 2006. Effect of ammonia production by Colletotrichum gloeosporioides on pelB activation, pectate lyase secretion, and fruit pathogenicity. Appl. Environ. Microbiol. 72:1034-1039.

Lee, R. H., and Chen, S. C. G. 2002. Programmed cell death during rice leaf senescence is nonapoptotic. New Physiol. 55:25-32.

Lee, S., Hong, J. C., Jeon, W. B., Chung, Y. S., Sung, S., Choi, D., Joung, Y. H., and Oh, B. J. 2009. The salicylic acid-induced protection of nonclimacteric unripe pepper fruit against Colletotrichum gloeosporioides is similar to the resistance of ripe fruit. Plant Cell Rep. 28:1573-1580.

Li, Y. F., Zhu, R., and Xu, P. 2005. Activation of the gene promoter of barley $\beta$-1,3-glucanase isoenzyme GIII is salicylic acid (SA)-dependent in transgenic rice plants. J. Plant Res. 118:215-221.
Lombardi, L., Ceccarelli, N., Picciarelli, P., and Lorenzi, R. 2007. DNA degradation during programmed cell death in Phaseolus coccineus suspensor. Plant Physiol. Biochem. 45:221-227.

MacKinnon, S. L., Keifer, P., and Ayer, W. A. 1999. Components from the phytotoxic extract of Alternaria brassicicola, a black spot pathogen of canola. Phytochemistry 51:215-221.

Manteau, S., Abouna, S., Lambert, B., and Legendre, L. 2003. Differential regulation by ambient $\mathrm{pH}$ of putative virulence factors secretion by the phytopathogenic fungus Botrytis cinerea. FEMS (Fed. Eur. Microbiol. Soc.) Microbiol. Ecol. 43:359-366.

Mariño, G., and Kroemer, G. 2010. Ammonia: A diffusible factor released by proliferating cells that induces autophagy. Sci. Signal. 124:pe19.

Mathieu, Y., Jouanneau, J. P., Thomine, S., Lapous, D., and Guern, J. 1994. Cytosolic protons as secondary messengers in elicitor-induced defense responses. BioChem. Soc. Symp. 60:113-130.

Matsumura, H., Nirasawa, S., Kiba, A., Urasaki, N., Saitoh, H., Ita, M. Kawai-Yamada, M., Uchimiya, H., and Terauchi, R. 2003. Overexpression of Bax inhibitor suppresses the fungal elicitor-induced cell death in rice (Oryza sativa L.). Plant J. 33:425-434.

Maxwell, D. P., and Lumsden, R. D. 1970. Oxalic acid production by Sclerotinia sclerotiorum in infected bean and in culture. Phytopathology 60:1395-1398.

Meir, S., Droby, S., Kochanek, B., Salim, S., and Philosoph-Hadas, S. 2005. Use of methyl jasmonate for suppression of Botrytis rot in various cultivars of cut rose flowers. Acta Hortic. 669:91-98.

Métraux, J. P., Signer, H., Ryals, J., Ward, E., Wyss-Benz, M., Gaudin, J., Raschdorf, K., Schmid, E., Blum, W., and Inverardi, B. 1990. Increase in salicylic acid at the onset of systemic acquired resistance in cucumber. Science 16:250:1004-1006.

Miyara, I., Davidzon, M., Sherman, A., and Prusky, D. 2010. pH Regulation of ammonia secretion by Colletotrichum gloeosporioides and its effect on appressorium formation and pathogenicity. Mol. PlantMicrobe Interact. 23:304-316.

Negrel, J., Vallee, J. C., and Martin, C. 1984. Ornithine decarboxylase activity and the hypersensitive reaction of tobacco to tobacco mosaic virus in Nicotiana tabacum. Phytochemistry 23:2747-2751.

Nitzan, N., Hazanovsky, M., Tal, M., and Tsror, L. 2002. Vegetative compatibility groups in Colletotrichum coccodes, the causal agent of black dot on potato. Phytopathology 92:827-832

Osbourn, A. E. 1996. Preformed antimicrobial compounds and plant defense against fungal attack. Plant Cell 8:821-1831.

Otani, H., Kohnobe, A., Kodama, M., and Kohmoto, K. 1998. Production of a hostspecific toxin by germinating spores of Alternaria brassicicola. Physiol. Mol. Plant Pathol. 43:205-227.

Packham, G., and Cleveland, J. L. 1994. Ornithine decarboxylase is a mediator of c-Myc-induced apoptosis. Mol. Cell Biol. 14:5741-5747.

Pageau, K., Reisdorf-Cren, M., Morot-Gaudry, J. F., and MasclauxDaubresse, C. 2006. The two senescence-related markers, GS1 (cytosolic glutamine synthetase) and $G D H$ (glutamate dehydrogenase), involved in nitrogen mobilization, are differentially regulated during pathogen attack and by stress hormones and reactive oxygen species in Nicotiana tabacum L. leaves. J. Exp. Bot. 57:547-557.

Peng, J., Deng, X., Huang, J., Jia, S., Miao, X., and Huang, Y. 2004. Role of salicylic acid in tomato defense against cotton bollworm, Helicoverpa armigera Hubner. Z. Naturforsch. Biosci. 59:856-862.

Prusky, D. 1996. Pathogen quiescence in postharvest diseases. Annu. Rev. Phytopathol. 34:413-434.

Prusky, D., and Lichter, A. 2007. Activation of quiescent infections by postharvest pathogens during transition from the biotrophic to the necrotrophic stage. FEMS (Fed. Eur. Microbiol. Soc.) Microbiol. Lett. 268:1-8.

Prusky, D., and Yakoby, N. 2003. Pathogenic fungi: Leading or led by ambient pH? Mol. Plant Pathol. 4:509-516.

Prusky, D., McEvoy, J. L., Leverentz, B., and Conway, W. S. 2001. Local modulation of host $\mathrm{pH}$ by Colletotrichum species as a mechanism to increase virulence. Mol. Plant-Microbe Interact. 14:1105-1113.

Prusky, D., Kobiler, I., Miyara, I., and Alkan, N. 2009 Mango fruit diseases. Pages 210-230 in: The Mango: Botany, Production and Uses, 2nd ed. R. E. Litz, ed. CAB International, Cambridge, MA, U.S.A

Reinehr, R., Gorg, B., Becker, S., Qvartskhava, N., Bidmon, H. J., Selbach, O., Haas, H. L., Schliess, F., and Haussinger, D. 2007. Hypoosmotic swelling and ammonia increase oxidative stress by NADPH oxidase in cultured astrocytes and vital brain slices. Glia 55:758-771.

Rollins, J. A., and Dickman, M. B. 2001. pH signaling in Sclerotinia sclerotiorum: Identification of pacC/RIM1 homolog. Appl. Environ. Microbiol. 67:75-81.

Ruzin, S. E. 1999. Plant Microtechniques and Microscopy. Oxford University Press, New York.

Sagi, M., Davydov, O., Orazova, S., Yesbergenova, Z., Ophir, R., Stratmann, J. W., and Fluhr, R. 2004. Plant respiratory burst oxidase 
homologs impinge on wound responsiveness and development in Lycopersicon esculentum. Plant Cell 16:616-628.

Sarowar, S., Lee, J. Y., Ahn, E, R., and Pai, H. S. 2008. A role of hexokinases in plant resistance to oxidative stress and pathogen infection. J. Plant Biol. 51:341-346.

Schaller, A., and Ryan, C. A. 1996. Molecular cloning of a tomato leaf cDNA encoding an aspartic protease, a systemic wound response protein. Plant Mol. Biol. 31:1073-1077.

Spoel, S. H., Johnson, J. S., and Dong, X. 2007. Regulation of tradeoffs between plant defenses against pathogens with different lifestyles. Proc. Natl. Acad. Sci. U.S.A. 104:18842-18847.

Stone, J. M.. Asai, T., Heard, J. E., and Ausubel, F. M. 2000. Investigating the mechanisms of programmed cell death in plants with a toxin from a necrotrophic fungus. Pages 411-415 in: Biology of Plant-Microbe Interactions, Vol. 2. P. J. G. M. de Wit, T. Bisseling, and W. J. Stiekema, eds. American Phytopathological Society Press, St. Paul, MN, U.S.A.

Su, Y., Li, T. L., Li, N., Yang, F. J., and Lu, S. W. 2009. Effects of salicylic acid on sucrose metabolism of tomato seedlings under $\mathrm{NaCl}$ stress. Ying Yong Sheng Tai Xue Bao 20:1525-1528.

Takahashi, H., Matsumura, H., Kawai-Yamada, M., and Uchimiya, H. 2008. The cell death factor, cell wall elicitor of rice blast fungus (Magnaporthe grisea) causes metabolic alterations including GABA shunt in rice cultured cells. Plant Signal. Behav. 3:945-953.

Tavernier, V., Cadiou, S., Pageau, K., Lauge, R., Reisdorf-Cren, M., Langin, T., and Masclaux-Daubresse, C. 2007. The plant nitrogen mobilization promoted by Colletotrichum lindemuthianum in Phaseolus leaves depends on fungus pathogenicity. J. Exp. Bot. 58:3351-3360.

Thaler, J., Owen, B., and Higgins, V. J. 2004. The role of the jasmonate response in plant susceptibility to diverse pathogens with a range of lifestyles. Plant Physiol. 135:530-538.

Thomma, B. P. H. J., Eggermont, K., Penninckx, I. A. M. A., Mauch-Mani, B., Vogelsang, R., and Cammue, B. P. A. 1998. Separate jasmonate-dependent and salicylate-dependent defense-response pathways in Arabidopsis are essential for resistance to distinct microbial pathogens. Proc. Natl. Acad. Sci. U.S.A. 95:15107-15111.

Thomma, B. P. H. J., Eggermont, K., Broekaert, W. F., and Cammue, B. P. A. 2000. Disease development of several fungi on Arabidopsis can be reduced by treatment with methyl jasmonate. Plant Physiol. Biochem. 38:421-427

Ton, J., Van Pelt, J. A., Van Loon, L. C., and Pieterse, C. M. J. 2002. Differential effectiveness of salicylate-dependent and jasmonate/ethylenedependent induced resistance in Arabidopsis. Mol. Plant-Microbe Interact. 15:27-34

Treutter, D. 2006. Significance of flavonoids in plant resistance: A review.
Environ. Chem. Lett. 4:147-157.

Tu, J. C. 1985. An improved Mathur's medium for growth, sporulation, and germination of spores of Colletotrichum lindemuthianum. Microbios 44:87-93.

Turci, M., Sardaro, M. L. S., Visioli, G., Maestri, E., Marmiroli, M., and Marmiroli, N. 2010. Evaluation of DNA extraction procedures for traceability of various tomato products. Food Control 21:143-149.

Turner, J. G., Ellis, C., and Devoto, A. 2002. The jasmonate signal pathway. Plant Cell 14:153-164.

Verhagen, A. M., Kratina, T. K., Hawkins. C. J., Silke, J., Ekert, P. G., and Vaux, D. L. 2007. Identification of mammalian mitochondrial proteins that Interact. with IAPs via N-terminal IAP binding motifs. Cell Death Differ. 14:348-357.

Verhoeff, K. 1974. Latent infections by fungi. Annu. Rev. Phytopathol. 12:99-110.

Verhoeff, K., Leeman, M., Vanpeer, R., Posthuma, L., Schot, N., and Vaneijk, G. W. 1988. Changes in $\mathrm{pH}$ and the production of organic acids during colonization of tomato petioles by Botrytis cinerea. J. Phytopathol. 122:327-336.

Walters, D. 2003. Resistance to plant pathogens: Possible roles for free polyamines and polyamine catabolism. New Phytol. 159:109-115.

Wildermuth, M. C., Dewdney, J., Wu, G., and Ausubel, F. M. 2001. Isochorismate synthase is required to synthesize salicylic acid for plant defense. Nature 414:562-65.

Yen, C. H., and Yang, C. H. 1998. Evidence for programmed cell death during leaf senescence in plants. Plant Cell Physiol. 39:922-927.

Yoda, H., Yamaguchi, Y., and Sano, H. 2003. Induction of hypersensitive cell death by hydrogen peroxide produced through polyamine degradation in tobacco plants. Plant Physiol. 132:1973-1981.

Yoshida, S., Ito, M., Nishida, I., and Watanabe, A. 2001. Isolation and RNA gel blot analysis of genes that could serve as potential molecular markers for leaf senescence in Arabidopsis thaliana. Plant Cell Physiol. 42:170-178.

Zhou, X., and Su, Z. 2007. EasyGO: Gene Ontology-based annotation and functional enrichment analysis tool for agronomical species. BMC Genomics.8: 246

\section{AUTHOR-RECOMMENDED INTERNET RESOURCES}

China Agricultural University Bioinformatics Center's EasyGo software: bioinformatics.cau.edu.cn/neweasygo

Weizmann Institution of Science Biological Services website: bioservices.weizmann.ac.il/microarrays/about.html 